\title{
REDUÇÃO DO ABSENTEÍSMO DE ENFERMAGEM EM UM AMBULATORIO DE SAÚDE MENTAL Gestão em Saúde
}

\section{INTRODUÇÃO}

O Ambulatório Médico de Especialidades de Psiquiatria é uma unidade especializada em saúde mental do Governo do Estado de São Paulo sob gestão de uma Organização Social. Realiza assistência aos portadores de transtornos mentais de média e alta gravidade na zona norte da cidade de São Paulo.

Os desafios na rotina da gestão deste ambulatório são inúmeros. Entre eles podemos citar o gerenciamento do absenteísmo de atendimentos de equipe multiprofissional.

O absenteísmo é um fator bastante importante e prevalente em serviços de saúde nacionais e internacionais e no âmbito ambulatorial se caracteriza pela ausência do paciente em atendimento agendado. Esse absenteísmo reflete impacto negativo de recursos humano, financeiro, administrativo e social. No âmbito dos atendimentos não médicos, os índices de absenteísmo são ainda mais alarmantes, podendo chegar entre 40 e $50 \%$.

Com base em dados de estudos e nos indicadores ambulatoriais do serviços, foi proposto um projeto de melhoria do absenteísmo através do gerenciamento das ausências em atendimentos de enfermagem utilizando a base teórica do Institute for Health care Improvement (IHI).

\section{OBJETIVO}

Reduzir o absenteísmo em atendimentos de enfermagem em 5\% (36\% para 31\%) em três meses a partir do início do projeto.

\section{MÉTODO}

Foi utilizado como ferramenta o formulário de PDSA do IHI para avaliação do projeto, a implantação inicialmente foi realizada em uma equipe de pequeno porte do ambulatório e posteriormente houve sua expansão.

- Ações iniciais de implantação do projeto: 1. Inclusão do Enfermeiro Gerente de Caso (GC) no projeto; 2. Sensibilização dos profissionais envolvidos no atendimento do paciente; 3. Adesão do profissional GC para monitoramento e busca ativa aos casos de falta.

- Ações para redução de absenteísmo: 1. Psicoedução intensificada junto ao paciente e familiares quanto a importância da adesão ao tratamento; 2 . Aprofundamento do real motivo da falta; 3 . Abordagem ativa do grupo para a questão de falta e não cumprimento do contrato terapêutico.

\section{RESULTADO}

Foram realizados 4 ciclos utilizando o formulário de PDSA do IHI, e conseguimos reduzir o absenteísmo no terceiro ciclo de $36 \%$ para $21 \%$ e no quarto ciclo de $21 \%$ para $8 \%$.

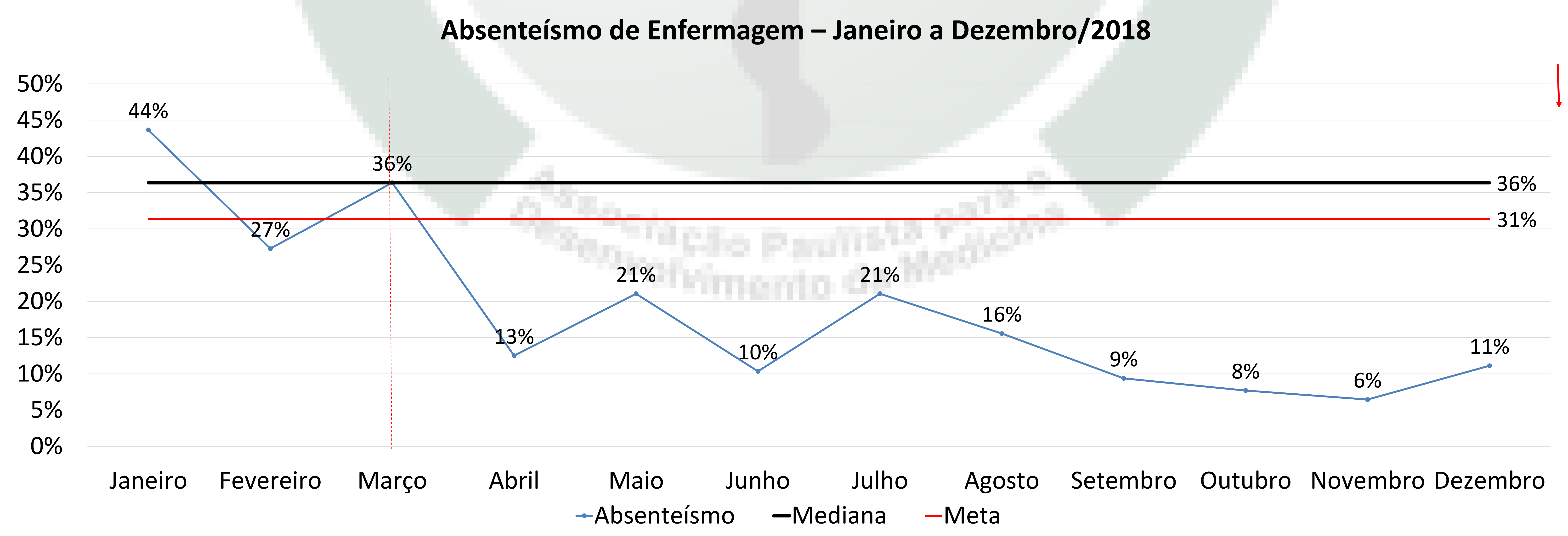

\section{CONCLUSÃO}

A escolha do modelo de melhoria como ferramenta da implementação de cultura de qualidade no ambulatório, nos trouxe ganhos muito importantes, dentre eles: 1. estruturação da tomada de decisões de uma forma clara e objetiva, com a ajuda do formulário PDSA do IHI; 2. motivação da equipe pelo aprendizado em cada ciclo; 3. possibilidade de melhor resposta ao tratamento; 4 . resultado significativo para um grande desafio da gestão: o absenteísmo. 